\title{
¿Cómo podemos asegurar que el traductor produzca un texto meta que sea comunicativamente equivalente y adecuado?
}

\author{
Gerd Wotjak \\ Universidad de Leipzig \\ wotjak@uni-leipzig.de
}

\section{Introducción}

La descripción científica de la milenaria actividad traductora, que tanto debe a la labor de nuestro homenajeado ${ }^{1}$, ha conocido un impulso considerable en estos últimos decenios, sin que aún se haya logrado un consenso sobre qué debe considerarse punto de referencia para, en esta actividad responsable y difícil, garantizar la producción de óptimos textos meta. El auge vertiginoso de jornadas dedicadas a la traductología así como de publicaciones monográficas especializadas, aparecidas también en español y en España, pero además en inglés, francés y -cómo no- en alemán, atestiguan el interés despertado por el multifacético fenómeno de la traducción, cuyo análisis -según Coseriu (1977) - ocupa un lugar destacado al tratarse de una ciencia-piloto y requiere la cooperación de múltiples y variadas disciplinas por considerarse una interdisciplina (Snell-Hornby 1988 y Snell-Hornby et al. 1994). En nuestra modesta contribución no dedicaremos atención a aspectos históricos relacionados con la traducción como comunicación bilingüe y transcultural mediada, en los que Julio-César Santoyo tam-

${ }^{1}$ Santoyo no sólo ha contribuido decisivamente al reconocimiento de la importancia de estudios científicos de la traducción, por ejemplo, al presentar una recopilación bibliográfica muy importante antes del boom traductológico, sino que ha instigado y enriquecido también la indagación de los fenómenos específicos que se dan en la traducción literaria impulsando y orientando al mismo tiempo otras investigaciones traductológicas en León y en otras universidades españolas (Santoyo 1985/ 1989, 1987, 1988, 1988a, 1999 y 2004). Puede considerarse pionero de estos estudios en la Península Ibérica al lado de García Yebra (1982). 
bién ha centrado su interés ${ }^{2}$, sino que nos limitaremos a los criterios que pueden utilizarse para evaluar la calidad de los textos meta producidos por los traductores. Si bien nos basaremos esencialmente en los postulados de la llamada Escuela Traductológica de Leipzig ${ }^{3}$, no nos proponemos hacer aquí un recuento de los aciertos y desaciertos de este enfoque. Tampoco detallaremos otros enfoques como el de la Escuela de Paris, de la teoría de los polisistemas y de la Manipulation School (Lefevere 1996 y Vidal Claramonte 1995; 1998), de los deconstructivistas, los descriptivistas (Toury 1995), etc. (Hurtado Albir 2001; Campos Plaza y Ortega Arjonilla 2005 y García Peinado y Ortega Arjonilla 2003), y sólo de pasada mencionaremos que, bajo la certera guía de J. C. Santoyo, Rabadán en 1991 ha desarrollado una visión interesante de la equivalencia.

Nos centraremos aquí, por un lado, en los aspectos vinculados con el eterno y siempre controvertido fenómeno de la equivalencia, tal como se ha venido tratando y modificando parcialmente desde Nida (1964 y 1975) hasta Koller (1992), pasando por Kade (1968 y 1980), Jäger (1975) y Neubert (1977 y 1985) como representantes más destacados de la Escuela de Leipzig ${ }^{4}$. Mencionaremos también, por otro lado, el imperante enfoque funcionalista que con su concepto del esco-

2 Sólo mencionaremos los varios congresos dedicados a esta temática y organizados bajo la orientación científica del homenajeado, todos en León, así como en muchos aportes al tema publicados en los 14 números de Livius: Revista de Traducción, creada por Santoyo y su equipo.

${ }^{3}$ Cf. Jung 2000; Wotjak 2006c y 2007b; los integrantes de este grupo heterogéneo ya han organizado 9 congresos internacionales sobre los aspectos fundamentales de la traducción desde el primer congreso celebrado en 1965 en Leipzig.

4 Para familiarizarse mejor con los logros y postulados de esta Escuela basta con leer los extractos de las publicaciones más importantes de los representantes principales y otros integrantes que hemos editado (Wotjak 2006c) bajo el título "50 Jahre Leipziger Übersetzungswissenschaftliche Schule. Eine Rückschau anhand von ausgewählten Schriften und Textpassagen" y contiene, además de 365 páginas reproducidas, otras 300 grabadas en un CD que lo acompaña. También mencionaremos la recopilación de artículos de más de 30 traductólogos, mayoritariamente alemanes, quienes en parte suministran una evaluación de los aciertos de la Escuela de Leipzig (Wotjak 2007b). Ya existe una versión portuguesa reelaborada (Cardozo, Heidermann y Weininger 2009) y se está preparando otra en español. 
po(s) ha pretendido sustituir la equivalencia y se ha ido propagando más allá de Alemania, también en el mundo hispanófono, ante todo por la meritoria e inagotable labor de Nord (1997 y 2002). A continuación dedicaremos especial atención a especificar lo que entendemos por equivalencia comunicativa, ya que existen muy variadas y no siempre bastante explícitas definiciones de este concepto, para nosotros básico, al igual que el concepto de la adecuación comunicativa, aún menos claramente descrito, pero ambos indispensables para poder asegurar que un texto meta reúne las propiedades esenciales y necesarias para considerarse una traducción lograda. En la primera parte empezaremos por esbozar los aspectos esenciales con referencias bibliográficas, para, en las siguientes partes, ampliar y especificar los conceptos más importantes, tales como equivalencia comunicativa, sentido comunicativo del texto con detalles semánticos y pragmáticos, relación entre lo semántico y lo cognitivo; convenciones textuales y la adecuación comunicativa.

\section{Presentación resumida de algunos conceptos teóricos esenciales para asegurar la equivalencia y adecuación comunicativas del texto meta}

El título escogido sugiere que, para poder hablar de un texto que cumpla cabalmente con la calificación de traducción, un texto meta debería ser comunicativamente equivalente al original, y al mismo tiempo también comunicativamente adecuado. Para muchos traductólogos el original ha sido el punto esencial de referencia de la labor traductora y, por lo menos para algunos (Nida 1964 y 1975; Newman 1980; Koller 1992; Rabadán 1991; Schreiber 1993; Jung 2000, 2003; Jung y Jiménez 2005; Pym 1998; Salevsky 2002; Lvovskaya 1997; Wotjak 1995, 1997), sigue siéndolo hoy en día, mientras que para los adeptos del escopo en la línea de Vermeer 1996 (cf. también Reiss y Vermeer 1996) el texto fuente sólo suministra al traductor una oferta informativa. En su actividad profesional este último debe priorizar el objetivo, la meta o el escopo encargado por el iniciador de la tarea traductora. La persona que encarga la traducción suele fijar el escopo que el texto meta ha de cumplir, lo cual puede tener como consecuencia que el traductor -en el caso de una variación de la función en- 
comendada- haya de adecuar su texto meta al objetivo, al escopo establecido, que en este caso diferirá, tal vez, mucho de la función comunicativa perseguida por el original. Al mismo tiempo el traductor debe tener en cuenta que el texto producido se adapte al máximo a los conocimientos previos compartidos por los receptores meta, que viven otra situación comunicativa, es decir, otro trasfondo sociocultural, $y$ que asimismo se adapte a las convenciones textuales vigentes del tipo o género de texto producido. Este enfoque prospectivo se está orientando, pues, casi exclusivamente a la producción del texto meta y está desantificando, destronando el original y la perspectiva retrospectiva, característica de los enfoques tradicionales que destacan la equivalencia, fidelidad o lealtad del texto meta con respecto al original y/o al autor del mismo.

Siguiendo las postulados de la Escuela Traductológica de Leipzig, podremos admitir como traducciones tan solo aquellos textos meta calificados como suficientemente equivalentes al original, y adecuados en lo que concierne a las normas textuales y discursivo-enunciativas vigentes en la comunidad lingüística y sociocultural, paracultural o diacultural, de los receptores meta (Wotjak 1995, 2002/2003 y 2006 b). Para nosotros, el concepto de equivalencia -lejos de identificarse con su definición matemática, que postula la biunivocidad entre traducción, retraducción y original- es gradual, y no implica que el efecto o valor comunicativo que el texto meta produce en los receptores meta haya de ser $100 \%$ congruente con el efecto o valor comunicativo que el original causaba en las mentes de los receptores fuente, ni tampoco con el efecto o valor comunicativo intencionado por el autor del original (Wotjak 1985). El texto meta producido por el traductor puede ser más o menos comunicativamente equivalente, es decir, puede contener desajustes y pérdidas, $\mathrm{y}$, por consiguiente, un mayor o menor grado de heterovalencia; pero una traducción nunca debe sobrepasar el límite mínimo extremo de $50 \%$ de equivalencia comunicativa. El traductor tiene que asegurar el mayor porcentaje posible de equivalencia, acercándose de forma óptima al ideal de equivalencia comunicativa total y absoluta e intentar una disminución máxima de la heterovalencia, algo no siempre evitable por completo. Si logramos, por ejemplo, un $90 \%$ de equivalencia comunicativa, quedará solamente un $10 \%$ de heterovalencia, inevitable por razones de diversidad sociocultural y lingüístico-estructural entre los receptores del original y del texto tra- 
ducido. Cuanto mayor sea el llamado diferencial sociocultural (Große y Neubert 1974) y tecnológico entre las comunidades fuente y meta, mayores serán las dificultades para lograr un texto meta óptimamente equivalente.

A pesar de tales dificultades, la obligación del traductor consiste en garantizar al máximo la constancia de las funciones ilocutivas o ilocucionarias entre original y texto meta, así como una óptima congruencia de la carga/función informativa-simbólica y/o apelativa entre los textos fuente y meta.

En el caso de un escopo que prioriza una variación de estas funciones y minimiza la influencia del original en la actividad traductora, optamos por no hablar de una traducción, de un texto meta traducido, sino que preferimos llamarlo adaptación, dado que presentará un porcentaje mayor de heterovalencia. En nuestra opinión, la equivalencia prima sobre la adecuación comunicativa, sin la que, sin embargo, el texto meta comunicativamente equivalente no puede considerarse una traducción óptima, por ejemplo, una traducción lista para publicación. ${ }^{5}$

Como esperamos poder demostrar detenidamente en la segunda parte, para garantizar la equivalencia comunicativa el traductor, lejos de descuidar las divergencias socioculturales existentes entre los receptores fuente y meta, las intentará compensar para adecuar así el texto meta a los receptores, más concretamente a los conocimientos previos de que aquellos disponen. Esperamos poder mostrar también que un análisis basado en la equivalencia comunicativa facilita una descripción más detallada, mejor fundamentada y más concisa que el recurso al escopo. Este último, por lo menos en el caso de una constancia de funciones, no se aparta tanto de nuestro enfoque como, a veces, se pretende sugerir. Y en el caso de una variación de las funciones ya no se trata de textos meta que puedan considerarse como traducciones con un grado suficiente de equivalencia comunicativa, y por ello no estarán en el punto de mira de nuestra actual contribución.

Para poder asegurar que un texto meta sea cabalmente equivalente al original tenemos que haber comprobado si logra coactivar en

\footnotetext{
${ }^{5} \mathrm{Cf}$. los tres niveles de realización de la traducción propuestos por la Escuela Traductológica de Leipzig - traducción bruta, traducción de trabajo y traducción lista para la publicación.
} 
la mente de sus receptores meta un sentido comunicativo mayoritariamente congruente con el sentido comunicativo que el texto fuente evoca en la mente de sus receptores, o sea, con el efecto o valor comunicativo realizado, que suele mostrar una coincidencia más o menos grande con el efecto comunicativo intencionado por el autor del original.

Admitimos que las conceptualizaciones evocadas en la mente de los receptores fuente y meta de hecho nunca coincidirán por completo. No podemos esperar una coincidencia total y absoluta de estas conceptualizaciones, siempre individuales, subjetivas y virtualmente mutables de un acto cognoscitivo a otro en un mismo individuo, ni mucho menos en varias personas, incluso en aquellos casos en los que los receptores pertenecen a una misma comunidad lingüística y sociocultural/ paracultural. Podemos, sin embargo, postular que coincidirán algunos elementos designativo-cognitivos, denotativo-referenciales y/o connotativo-evaluativo-emotivos por haberse socializado y almacenado en las conceptualizaciones individuales, constituyendo un núcleo común y compartido de los conocimientos previos de los receptores de una misma comunidad lingüística y paracultural.

Se puede postular una mayor o menor coincidencia de los conocimientos previos también entre receptores pertenecientes a una misma comunidad diacultural en el seno de la misma comunidad lingüística y paracultural. No excluimos tampoco que los conocimientos previos disponibles entre miembros de distintas comunidades lingüísticoparaculturales, pero que pertenecen a una misma diacultura musical, ideológico-moral o profesional, contengan una mayor cantidad de elementos socializados compartidos. Con ello no pasamos por alto el hecho de que los conocimientos previos o conceptualizaciones individuales o ideoculturales de personas pertenecientes a una misma diacultura, pero a diversas comunidades lingüístico-paraculturales, contengan, además de conocimientos coincidentes, también una cantidad mayor o menor de elementos designativos socializados divergentes. El traductor tiene que ser consciente de estas divergencias y buscar soluciones para obtener con el texto meta la evocación de una congruencia máxima en la mente de sus receptores.

Los participantes en la interacción social indispensable en el seno de una comunidad lingüístico-paracultural, pero también diacultural, han adquirido a lo largo de múltiples actos cognoscitivos y comu- 
nicativos interpersonales un determinado conjunto de elementos cognitivo-designativos, denotativo-referenciales y connotativo-apreciativo-emotivos que llevan interiorizados como componentes nucleares de sus conceptualizaciones individuales e ideoculturales. Además de las configuraciones cognitivas / CC compartidas, las llamadas escenas (Fillmore 1976), los escenarios, scripts (Raskin 1985 y 1986), Geschehenstypen (Klix 1987), pequeños dramas (Tesnière 1959), etc., han adquirido asimismo un número más o menos considerable y cambiante de elementos cognitivos idiosincrásicos y subjetivos.

Estos últimos -si bien existen y pueden coactivarse, dado el caso- no deben tenerse en cuenta para postular y juzgar el logro de la comunicación interpersonal intralingüística y/o en el seno de una paracultura o diacultura, o bien de una comunicación transcultural e interlingüística, permitida por la traducción, o incluso también -en mayor o menor grado- por la adaptación en forma de un texto meta dominantemente heterovalente respecto al original.

Basta con que las configuraciones cognitivas (CC) coactivadas en la mente de los receptores fuente y meta integren una cantidad suficiente de copartícipes o actuantes congruentes del pequeño drama o de las escenas o los escenarios, scripts/guiones, etc. Parece que en la literatura traductológica se prefiere hablar de escenas siguiendo una sugerencia de Vannerem y Snell-Hornby (1986). Se trata en estos casos, como también en otras CC, cuyo tamaño y contenido puede variar, de estructuraciones cognitivas o representaciones convencionalizadas y estructuradas del conocimiento enciclopédico y sociocultural compartido. Estas CC se encuentran almacenadas bajo la forma de conocimientos nucleares compartidos de los conocimientos previos o conceptualizaciones individuales.

No les resulta a los traductores tarea nada fácil intentar compensar eventuales lagunas designativas, pero suele ser menos complicado que reestructurar las $\mathrm{CC}$ o eliminar de estas $\mathrm{CC}$ meta determinados partícipes no admitidos o coactivados por la CC fuente. Resulta particularmente difícil obstaculizar la evocación de rasgos designativos compartidos en las conceptualizaciones y conocimientos previos de los receptores meta que designan aspectos connotativos, en especial negativamente evaluados, donde en la $\mathrm{CC}$ fuente no aparece ningún rasgo parecido o incluso donde aparece un rasgo apreciativo positivo. Opinamos que en este último caso el traductor no podrá evitar una 
cierta divergencia en los valores o efectos comunicativos fuente y meta, al igual que en aquellos casos donde los receptores meta suelen coactivar automáticamente una $\mathrm{CC}$ suplementaria junto a la $\mathrm{CC}$ coactivada en concordancia con la CC evocada en el texto fuente y donde esta $\mathrm{CC}$ meta suplementaria introduce rasgos denotativo-referenciales y designativo-connotativos difíciles y hasta imposibles de eliminar por los esfuerzos traductivos.

La tarea del traductor que se esfuerza por obtener una congruencia óptima entre las CC fuente y meta coactivadas en las mentes de los receptores fuente y meta por los respectivos textos (original y traducción) se ve dificultada allí donde no coinciden cabalmente las CC y sus interrelaciones con otras $\mathrm{CC}$. Ya que las $\mathrm{CC}$ constituyen factores esenciales del mensaje textual y del sentido comunicativo textual y discursivo, debe darles mayor prioridad. Donde mayores obstáculos tiene que vencer, es, sin embargo, no donde hay un déficit de rasgos congruentes, sino donde abundan los rasgos suplementarios y/o divergentes en las CC meta o donde se enfrenta con la evocación automática de una CC suplementaria en la mente de los receptores meta, es decir, donde hay una plétora de carga designativa meta o una gran cantidad de rasgos idiosincrásicos peculiares meta, especialmente de índole connotativo-emotiva-apreciativa opuesta o distinta.

Hasta ahora hemos señalado la importancia primordial de fenómenos cognitivos en la producción de textos meta comunicativamente equivalentes, y destacado también la existencia de conocimientos previos compartidos entre receptores pertenecientes a una misma comunidad lingüístico-(para)cultural. Asimismo hemos subrayado la improbabilidad de que las configuraciones cognitivas coactivadas o coactivables del conocimiento enciclopédico (del mundo, de las cosas) y sociocultural socializado y almacenado en las mentes de los receptores fuente coincidan totalmente con las CC memorizadas por los receptores de la comunidad idiomático-cultural meta. Hemos postulado también que puede haber mayor congruencia entre las CC socializadas almacenadas por receptores pertenecientes a una misma diacultura, pero a distintas paraculturas y lenguas.

Esto es particularmente probable en textos de alto grado de especialización científica, por ejemplo, en textos de ciencias exactas, donde la tematización de aspectos de la vida sociocultural y, por ende, de fenómenos de la paracultura y de la praxis interaccional y comuni- 
cativa diaria es prácticamente nula. Por ello podemos postular que la traducción de textos fuente producidos por autores expertos y destinados a expertos en la misma materia de la comunidad meta ofrece las mayores posibilidades de obtener un muy alto grado de equivalencia comunicativa, siempre y cuando el propio traductor sea capaz de actuar como experto en esa materia tanto en lo que concierne a la comprensión del texto, es decir, a la deducción de su sentido comunicativo, como en lo concerniente a la producción de un texto meta en el que se respeten los conceptos terminológicamente acuñados y las convenciones textuales meta virtualmente divergentes.

Aumentará la dificultad objetiva de garantizar un texto meta comunicativamente equivalente cuando éste tematiza aspectos de la vida diaria, es decir, allí donde la incidencia de aspectos paraculturales fuente es considerablemente mayor; el traductor tendrá que resignarse a aceptar ciertas pérdidas irreparables e incongruencias inevitables entre el sentido comunicativo del original y el texto meta. El receptor meta, tal vez, ni se percatará de estas carencias o desperfectos, y el traductor podrá consolar su mala conciencia profesional pensando que no todas las $\mathrm{CC}$ del texto fuente tienen la misma pertinencia para la captación del mensaje y de la progresión temática, y que una determinada carencia en el texto meta tiene escasa repercusión en el grado de equivalencia comunicativa alcanzado. ${ }^{6}$

\section{El sentido comunicativo del texto como criterio esencial}

Hasta ahora hemos destacado la inmensa importancia que, para garantizar un texto meta óptimamente equivalente, tiene una máxima congruencia en las respectivas $\mathrm{CC}$ evocadas por los textos y discursos en cuestión, CC que designan: eventos, estados de cosas, propiedades, actividades, procesos, objetos físicos, artefactos, personas o animales, relaciones, pero también emociones, apreciaciones, etc. Con ello abordamos componentes esenciales e indispensables que deben guiar al traductor en su afán de crear un texto meta cuyo mensaje sea cabalmente congruente con el mensaje vehiculado por el texto fuente. Pero

\footnotetext{
${ }^{6}$ Cf. la teoría de la relevancia que Gutt (1991) ha adaptado a la traducción basándose en la de Sperber y Wilson (1986).
} 
hasta ahora no hemos especificado cómo se evocan las CC en las mentes de los receptores, ni hemos abarcado la totalidad de los factores que conforman el sentido comunicativo del texto, criterio fundamental para juzgar el grado de equivalencia comunicativa obtenido en la producción del texto meta. Falta por tener en cuenta, además del mencionado mensaje, también la intención comunicativa o función ilocucionaria/ ilocutiva, lo que el autor ha querido decir u obtener (objetivo perlocutivo) con su texto.

Este último aspecto se superpone a lo que dice o comunica el texto, al mensaje transmitido, y da lugar a múltiples modificaciones o relecturas interpretativas de este último, ello en tanto en cuanto no coincida con la función informativo-designativa siempre presente en cualquier acto comunicativo-discursivo-enunciativo. No podemos acceder, pues, a una interpretación / comprensión cabal del sentido comunicativo del texto fuente, indispensable para intentar su reproducción máximamente congruente en el texto meta, sin tener en cuenta el mensaje y lo que ha querido decir.

También la Escuela de París ha hecho hincapié en la importancia primordial del sentido (Seleskovitch y Lederer 1984; Lederer 1994; una revisión crítica por Sáez Hermosilla 1994) y la respectiva desverbalización e inevitable reverbalización del texto meta a partir de este sentido desvinculado de la forma utilizada para coactivarlo (Wilss 1996). Pero, que sepamos, no se ha intentado especificar lo suficiente lo que se entiende por sentido y cómo se puede concretar su descripción. Creemos que para ello podemos recurrir a una tripartición propuesta por Ducrot ya en 1972, quien distingue:

A. lo puesto (le posé),

B. lo supuesto (supposé) y

C. lo que ha querido decir el autor, factor que opera sobre A y B, que conjuntamente constituyen el mensaje textual.

Al hablar de lo puesto, nos centramos fundamentalmente en lo dicho, lo mayoritariamente materializado por recursos lingüísticos en los textos y los contenidos coactivados en la mente de los usuarios, ante todo, mediante las unidades léxicas. Estas últimas, como unidades conformadas por la forma y el contenido, planos de la expresión y del contenido respectivamente (ver tabla 1), disponen de un potencial designativo-referencial y connotativo-apreciativo así como combinatorio-sintagmático morfosintáctico y sememotáctico, asimismo de ca- 
racterísticas pragmático-comunicativo-situativo-estilísticas también ubicadas en el plano de la expresión. Las llamadas microestructuras semémicas ${ }^{7}$ aparecen en el plano del contenido indisolublemente relacionadas con las formas citativas o cuerpos sígnicos. Éstos están materializados bajo la forma de secuencias (alo)fónicas y grafemáticas y de

Tabla 1. Potencial comunicativo de las unidades léxicas (Wotjak 1994)

\begin{tabular}{|c|c|c|c|}
\hline A. & Plano de la expresión & I. & Plano del contenido \\
\hline & plano significante (Trujillo 1988) & & \\
\hline A.1 & Significante / Formativo $\rightarrow$ Cuerpo sígnico & I.1 & $\begin{array}{l}\text { Microestructura } \\
\text { semémica }\end{array}$ \\
\hline A. 2 & Indicaciones Morfosintácticas & & \\
\hline A.2.1 & Especificaciones categoriales y subcategoriales & $\mathrm{I} .2$ & $\begin{array}{l}\text { Medioestructura } \\
\text { semántica }\end{array}$ \\
\hline A.2.2 & $\begin{array}{l}\text { Especificaciones combinatorio-distribucionales } \\
\text { (morfosintácticas) }\end{array}$ & & \\
\hline A.2.2.1 & Valencia morfosintáctica & & \\
\hline A.2.2.2 & $\begin{array}{l}\text { Distribución morfosintáctica; } \\
\text { Entorno del cotexto }\end{array}$ & & \\
\hline A. 3 & Distribución sememotáctica; & I.3 & $\begin{array}{l}\text { Macroestructura } \\
\text { paradigmática semántica }\end{array}$ \\
\hline A.3.1 & Valencia semántica (Helbig 1992) & & \\
\hline A.3.2 & Entorno cotextual alosémico & & \\
\hline A. 4 & $\begin{array}{l}\text { Especificaciones comunicativo-situativo- } \\
\text { pragmáticas }\end{array}$ & & \\
\hline A. 4.1 & $\begin{array}{l}\text { Preferencias de uso en determinados tipos } \\
\text { textuales / esferas counicativas }\end{array}$ & & \\
\hline A. 4.2 & Marcas diatópicas & & \\
\hline A.4.3 & Marcas diastráticas & & \\
\hline A. 4.4 & Marcas diafásicas & & \\
\hline A. 4.5 & Marcas diageneracionales & & \\
\hline A. 4.6 & $\begin{array}{l}\text { Especificaciones valorativas / especificaciones } \\
\text { axiológicas (connotaciones) }\end{array}$ & & \\
\hline A. 5 & $\begin{array}{l}\text { Construcciones de formación de palabras } \\
\text { permitidas / familias de palabras }\end{array}$ & & \\
\hline
\end{tabular}

${ }^{7}$ Así como las medio y macroestructuras semánticas paradigmáticas que aquí no podremos tratar (Wotjak 2006a). 
sus respectivas especificaciones morfosintácticas categoriales, sintagmáticas, combinatorias, distribucionales (por ejemplo, la valencia verbal) y comunicativas stricto sensu.

Las unidades léxicas -como recursos más importantes de lo puesto- constituyen lo dicho y aportan -junto con su forma- un determinado significado léxico, una microestructura semémica de entre las varias que suelen aparecer asociadas con el cuerpo sígnico o significante homógrafo y homófono en cuestión. En combinación con otras unidades léxicas y sus respectivos significados, seleccionados de entre el conjunto de microestructuras que confeccionan las medioestructuras correspondientes, se conforman las así llamadas macroestructuras semánticas sintagmáticas oracionales y transfrástico-textuales.

A lo que dice o comunica el texto, al mensaje transmitido, se superpone lo que ha querido decir el autor del texto fuente. Esta intención perseguida por el autor, que el traductor debe deducir del texto fuente en su contexto enunciativo-discursivo, puede dar lugar a múltiples modificaciones o relecturas interpretativas. No podemos garantizar una interpretación/comprensión cabal del sentido comunicativo del texto fuente, indispensable para intentar su reproducción máximamente congruente en el texto meta, sin tener en cuenta el mensaje y lo que ha querido decir.

\subsection{Algunas aclaraciones relativas al significado del léxico común, en especial de verbos, y primer acercamiento a su supuesta relación con la cognición.}

Nos llevaría demasiado lejos detallar aquí todos los aspectos; nos limitaremos, pues, a esbozar a continuación las supuestas interdependencias existentes entre los significados léxicos y la cognición. Trataremos en concreto la relación del significado con las configuraciones cognitivas ya mencionadas, que, a nuestro modo de ver, pueden, pero no deben coactivarse siempre en su totalidad por los significados léxicos de las respectivas unidades léxicas en la comunicación interpersonal diaria (a los interesados les invitamos a leer Wotjak 2006). Para nosotros, el significado léxico es una entidad lingüística y cognitiva a la vez; constituye la piedra angular que relaciona lo lingüístico-semántico con lo cognitivo-mental y extralingüístico (véase la propuesta de un significado de dos niveles de Bierwisch 1983 - en Wotjak 2006, y 
también en Wotjak 2006a, 2007). El significado léxico como entidad cognitiva sui generis está integrado por elementos o rasgos cognitivodesignativos tanto denotativo-referenciales como también designativo-connotativos, pertenecientes a las respectivas $\mathrm{CC}$; pero sólo en casos excepcionales congruyen por completo las microestructuras semémicas y las configuraciones cognitivas que pueden, pero no deben coactivarse en la mente de los hablantes.

En nuestra opinión, el significado léxico se compone de una configuración nuclear designativa que la unidad léxica en cuestión suele compartir, por regla general, con varias otras unidades léxicas sinonímicas, antonímicas y cohipónimas. Esta configuración nuclear semémica suele constituir una especie de denominador común archisemémico para varias unidades léxicas designativamente afines, ya que suelen poder evocar CC genéricas o ya especializadas más o menos congruentes, o sea, suelen instanciar o referenciar un estado de cosas o un evento, proceso, etc. idéntico o bastante similar.

En el caso de microestructuras semémicas de verbos, estas configuraciones archisemémicas comprenden, además de functores o predicado(re)s, un conjunto de casillas vacías o slots argumentales que predeterminan aquellas unidades léxicas que en la construcción oracional pueden utilizarse para llenar dichas casillas. Estas unidades léxicas "de relleno" con su papel temático atribuido ocupan los respectivos slots argumentales del semema verbal y deben satisfacer también las restricciones combinatorias del tipo semántico-categorial o clasemático, es decir, debe tratarse de personas $<$ Hum $>$, $<$ objetos físicos $>$, $<$ procesos $>$, etc.

Pueden aparecer, además de los argumentos variables o variables argumentales o slots, también algunos argumentos constantes, por lo menos en algunos verbos; así INSTRUMENTO / < pies> para caminar; AGENTE / < perro> para ladrar; o LOC / <objeto físico / recipiente> para empaquetar. Tales indicaciones combinatorio-sintagmáticas para los complementos o actantes del verbo pueden ser obligatorias o facultativas, es decir, llenarse en la combinatoria verbal sólo cuando son relevantes para la comunicación, para lo que quiere decir / informar el locutor / autor.

Para nosotros, las casillas argumentales, al igual que los argumentos constantes del semema (verbal), se corresponden con determinados copartícipes de la configuración cognitiva correlacionada (cf. la 
escena del tratamiento médico en la figura 2), pero los significados léxicos, por regla general, no suelen abarcar la totalidad de los copartícipes coactivables y pertenecientes a la CC memorizada. Se ha efectuado una selección influida por la coexistencia de otras unidades léxicas con sememas más o menos semejantes, y el potencial o la estructura argumental del semema es el resultado de una sememización, una socialización y usualización idiomático-social y culturalmente condicionadas.

No les resulta a los traductores tarea nada fácil intentar compensar eventuales lagunas designativas, pero suele ser menos complicado que reestructurar las configuraciones cognitivas o eliminar de estas CC meta determinados partícipes no admitidos o coactivados por la $\mathrm{CC}$ fuente. Resulta particularmente difícil obstaculizar la evocación de rasgos designativos compartidos en las conceptualizaciones y conocimientos previos de los receptores meta que designan aspectos connotativos, en especial negativamente evaluados, donde en la CC fuente no aparece ningún rasgo parecido o incluso donde aparece un rasgo apreciativo positivo. Opinamos que en este último caso el traductor no podrá evitar una cierta divergencia en los valores o efectos comunicativos fuente y meta, al igual que en aquellos casos donde los receptores meta suelen coactivar automáticamente una $\mathrm{CC}$ suplementaria junto a la CC coactivada en concordancia con la $\mathrm{CC}$ evocada en el texto fuente y donde esta $\mathrm{CC}$ meta suplementaria introduce rasgos denotativo-referenciales y designativo-connotativos difíciles y hasta imposibles de eliminar por los esfuerzos traductivos.

El significado de norma y/o de sistema (Wotjak 2006 y 2006a) que nos interesa resulta de una triple abstracción y/o generalización: (1) se trata de una abstracción por socialización, es decir, sólo lo integran aquellos rasgos designativos que aparecen compartidos en las CC de los núcleos conceptuales de virtualmente todos los hablantes de una lengua histórica común o por lo menos de un grupo socio-, dia- o tecno-lectal; (2) se trata de una usualización con la consecuencia de que forman parte del significado aquellos rasgos sémicos y designativos socializados que reaparecen indicados en prácticamente todos los usos co- y contextuales de la variante léxica con el semantismo en cuestión; (3) se trata de una abstracción o generalización de índole epistemológico-ontológica, ya que estamos tratando con una categoría, un prototipo, una clase o un conjunto o genus proximum donde sólo aparecen 
algunos rasgos designativos considerados como válidos para prácticamente todos los ejemplares o elementos de la clase/ categoría o del prototipo a los que puede referirse la unidad léxica con su significado, es decir, con relación a los ejemplares o elementos que constituyen la extensión de la "noción" en cuestión.

La microestructura semémica verbal no sólo se compone de argumentos que junto con los functores conforman el potencial o la estructura argumental de la variante semántica de un verbo polisémico u homonímico. Los argumentos y functores constituyen la configuración nuclear designativa sincrónicamente invariable del significado léxico de la unidad léxica en cuestión. Su significado suele integrar, además, otros rasgos designativo-sémicos mediante los que algunas diferenciaciones ulteriores se atribuyen a una misma o semejante referencia extralingüística. ${ }^{8}$ Los comunicantes suelen no designar solo los aspectos referenciales, sino que también expresan, como componentes sememizados de las microestructuras semémicas inherentes a las palabras escogidas, evaluaciones, tomas de postura frente a los hechos referidos y emociones. Estos componentes modificadores o diferenciadores intrasemémicos son mayoritariamente idiosincrásicos y responsables de la distinción más o menos sutil en unidades léxicas sinonímicas, por ejemplo, entre verbos como regalar, donar, dar, legar; enviar, entregar. Todos ellos implican un cambio de posesión o disposición: el poseedor aparece como la persona que da algo a otra, con especificación de otros factores de la transmisión: ese algo pertenece luego a la persona que lo recibe (regalado, donado), o bien no se especifica que el destinatario de la acción pueda quedarse con lo dado como propiedad suya (entregar, enviar), o bien que la acción sólo se efectúa después de la muerte del que lo desea dar (legar) ${ }^{9}$, etc.

Para nosotros, el significado léxico suele ser bastante genérico y permite contentarse con la evocación de rasgos cognitivos bastante ge-

${ }^{8}$ Se trata de aquellos rasgos sémicos que la lexemática y la semántica europea estructural han destacado (mayoritaria o incluso exclusivamente) como significativos ya que establecen oposiciones o divergencias entre dos o más unidades léxicas y sus respectivos significados de norma o sistema (Wotjak 2006b).

${ }^{9}$ Para más detalles al respecto cf. Wotjak 2006a, donde se analiza, ante todo, el par de verbos alemanes rauben / berauben y stehlen / bestehlen especificando sus microestructuras así como las actantificaciones morfosintácticas correspondientes. 
néricos; en no pocos casos, el significado léxico con sus indicaciones genéricas nos parece suficiente para asegurar una comprensión lo suficientemente clara y cabal. Funciona como una llave maestra que abre todas las puertas individuales, para sacar del inventario inconmensurable de elementos cognitivos (en última instancia individuales y subjetivos) guardado detrás de esas puertas un mínimo común de rasgos noemático-cognitivos compartidos. El hablante concreto no se siente obligado a abrir la puerta por completo para sacar todos los componentes acumulados de las conceptualizaciones respectivas. Si esto fuera inevitable, nos desbordaría a cada momento un sinnúmero más o menos impresionante de rasgos cognitivos individuales y subjetivo-situativos, lo cual podría sobrecargar la memoria de trabajo disponible.

El interlocutor no precisa siempre la movilización de conocimientos más pormenorizados y específicos, sino que se contentará, por ejemplo, con aquellos representados en la simbolización genérica del núcleo semémico designativo para la noción / predicación de "mejorar la calidad de algo" en (1).

(1) configuración nuclear genérica para veredeln (igualmente válida para "mejorar, abonar..."):

[HAVE $(\mathrm{y}, \mathrm{z})] \mathrm{ti}$ ET $\left[\operatorname{OPER}(\mathrm{x}, \mathrm{w}) \& \operatorname{CAUSE}\left(\mathrm{x},\left(\operatorname{HAVE}\left(\mathrm{y}, \mathrm{z}^{\prime}\right)\right)\right] \mathrm{ti}+\mathrm{k}\right.$

Functores:

HAVE $=$ poseer (o disponer) un argumento y (de) algo / $\mathrm{z}$

$\mathrm{OPER}=$ utilizar un argumento $\mathrm{x}$ un argumento $\mathrm{w}$

CAUSE $=$ causar $\mathrm{x}$ algo $/$ proposición

Slots argumentales:

$\mathrm{x}=$ CAUSADOR $/$ AGENTE $/<$ Hum $>$

$\mathrm{y}=$ DESTINATARIO $/<$ Planta $>$ vs. $<$ Objeto físico $>$

$\mathrm{Z}=$ TEMA $/<$ calidad $/$ propiedad determinada $>$

$\mathrm{Z}^{\prime}=$ TEMA $/<$ calidad mejorada $>$

$\mathrm{w}=$ INSTRUMENTO $/<$ Ofis $>$ 
Para poder utilizar en alemán el verbo archilexemático veredeln, que muy bien recubre con su significado la predicación indicada, debemos acudir primero a nuestro conocimiento enciclopédico para decidir lo que se suele mejorar prototípicamente: $<\mathrm{ALGO}>\rightarrow$ acero, árboles frutales, fibras textiles... Si nos decidimos, por ejemplo, por un árbol frutal, sólo algunos hablantes nativos activarán en su conocimiento previo cómo se suele obtener esta mejora, mientras que todos van a activar de común acuerdo el objetivo perseguido con esta actividad: "mejorar la calidad" de las frutas (cereza, ciruelas, manzanas, etc.).

No nos hace falta conocer las tecnologías utilizables en tales operaciones, ya que nos solemos contentar con la designación actualizada por el semantismo verbal, sin recurrir forzosamente a otros elementos de lo supuesto o sobreentendido coactivable o coactivado, por ejemplo, por los jardineros. Creemos que, en un discurso no especializado en horticultura, para la mayoría de los hablantes del alemán es comunicativa y designativamente suficiente lo que pone a disposición la unidad léxica veredeln con su potencial designativo y comunicativo-combinatorio.

Podríamos postular que, para el aseguramiento necesario del sentido comunicativo textual, por lo general no es menester invocar o coactivar las CC en su totalidad, sino que nos contentamos, por lo menos en el discurso no especializado de todos los días sobre objetos y sectores del dominio designativo cotidiano, con lo que aporta el significado léxico con sus rasgos cognitivos socializados y usualizados y además bastante genéricos. Las escenas, tan importantes para asegurar la progresión temática de los textos, ya suelen ser generalmente más concretas, ya que allí aparecen los verbos junto con determinadas unidades léxicas "de relleno" que ya han concretado los copartícipes de las CC indicadas por los verbos a través de sus slots argumentales semémicos. Estas escenas predican sobre actividades, eventos, procesos vividos que los comunicantes de una determinada comunidad para y/o diacultural e idiomática han memorizado, motivados por el interés que han despertado en ellos. Los significados verbales, por el contrario, aparecen como unos esquemas con casillas vacías semánticamente predeterminadas por el papel temático que cumplen y las características clasemáticas genéricas que deben ostentar aquellas entidades que pueden aparecer como co-partícipes concretos de la CC coactivada. El potencial designativo y combinatorio comunicativo del 
semantismo de unidades léxicas verbales no sólo genera oraciones sino también instancia o instaura predicaciones, configuraciones cognitivas más o menos concretas y/o especializadas.

\subsection{El semantismo de unidades léxicas terminologizadas}

Los significados léxicos de las palabras, que designan aspectos de la vida diaria e instancian predicaciones sobre sectores y objetos del dominio designativo igualmente pertinentes para la práctica totalidad de los integrantes de una misma comunidad idiomático-paracultural, se diferencian de los conceptos científicos, bien definidos en cuanto a intensión y extensión, es decir, que reúnen un conjunto de elementos designativos bien delimitados y discretos cuya cantidad y calidad no suelen insinuar ningún matiz de vaguedad ni de subjetividad. Estos contenidos, que no identificaremos aquí con las microestructuras semémicas, característicos para el correlato mental de los significantes terminológicos, no sólo están bien definidos en cuanto a la cantidad y calidad de sus componentes cognitivos, sino que, de hecho, suelen poder coincidir más allá de un determinado idioma en las mentes de comunicantes que pertenecen a comunidades idiomático-diaculturales muy parecidas. Este postulado nos parece tener mucha probabilidad, por lo menos en el caso de las ciencias exactas, donde priman los componentes denotativo-referenciales sobre los designativo-connotativos. Menos probable parece ser la congruencia de contenidos terminológicos en las ciencias sociales, donde, por ejemplo, palabras claves como democracia o libertad reciben interpretaciones ideológico-político-filosóficas bastante divergentes.

Ya habíamos señalado que la gran coincidencia de los conocimientos previos almacenados por expertos de una misma, pero también de distintas comunidades idiomático-paraculturales, facilita teóricamente el trabajo del traductor. Sin embargo, también puede enfrentarse en la traducción de textos muy especializados con dificultades que no derivan solo de factores subjetivos, es decir, de carencias en los conocimientos especializados de los que dispone el traductor. Esto ocurre si la comunidad meta, para la cual debe producir un mensaje óptimamente congruente/ equivalente, no dispone de los conceptos y de los términos para los objetos referenciales. No podemos excluir que los receptores meta coactiven CC mayoritariamente divergentes inclu- 
so dentro de una misma comunidad idiomático-paracultural, si se trata de mensajes destinados a expertos, que intentan comprender legos en la materia.

Con textos que tematizan aspectos de la vida diaria fuente, máxime en textos literarios (históricos o no), aumentarán las dificultades de traducción allí donde las palabras meta con un potencial designativo-referencial adecuado activan en la mente de los receptores meta rasgos designativo-connotativos distintos que no pueden neutralizarse comunicativamente.

\subsection{Algunas consideraciones sobre implicaciones cognitivas para la traducción}

Tanto en la comunicación monolingüe entre personas pertenecientes a una misma comunidad idiomático-paracultural como también en la comunicación entre personas pertenecientes a distintas comunidades idiomático-paraculturales y que necesitan recurrir a un mediador (traductor) o a un idioma conocido por los hablantes de la lengua 1 y de la lengua 2, las palabras utilizadas suelen evocar un determinado núcleo común y compartido en las conceptualizaciones siempre individuales y situativo-enunciativas hic et nunc, automáticamente asociadas en las mentes de los comunicantes. El usuario concreto e individual de una lengua determinada, sin embargo, no suele activar siempre en una palabra dada la totalidad de los elementos socializados que él mismo o los otros hablantes de la misma comunidad comunicativa tienen almacenados como núcleo común en sus respectivos conocimientos previos, pero siempre va a activar por lo menos aquellos rasgos de las CC que se encuentran sememizados, es decir, que, además de haberse socializado entre todos los hablantes nativos de una misma lengua histórica, también se han usualizado y que aparecen como componentes "congelados" y sincrónicamente invariables en los significados léxicos vehiculados por las unidades léxicas en cuestión.

Puede haber divergencias menores o mayores con respecto a los elementos designativos, tanto denotativo-referenciales como connotativos, que se han socializado conformando el núcleo común de los conocimientos previos individuales. La conformación de estas configuraciones cognitivas / CC socializadas se efectúa, de forma inconsciente, en repetidos actos designativo-referenciales, y estas configuracio- 
nes cognitivas se confirman como conocimientos compartidos en repetidos actos comunicativos en el seno de determinadas comunidades para y/o diaculturales que utilizan una misma lengua histórica o sus posibles diasistemas (sociolectos, tecnolectos, regiolectos etc.). No es de extrañar que se manifiesten divergencias más o menos grandes en cuanto a la cantidad y calidad de los copartícipes involucrados en la $\mathrm{CC}$, una escena o un Geschehenstyp (fig. 2, por ejemplo).

Fig. 2. Geschehenstyp / CC BEHANDELN = TRATAMIENTO médico (Klix 1987)

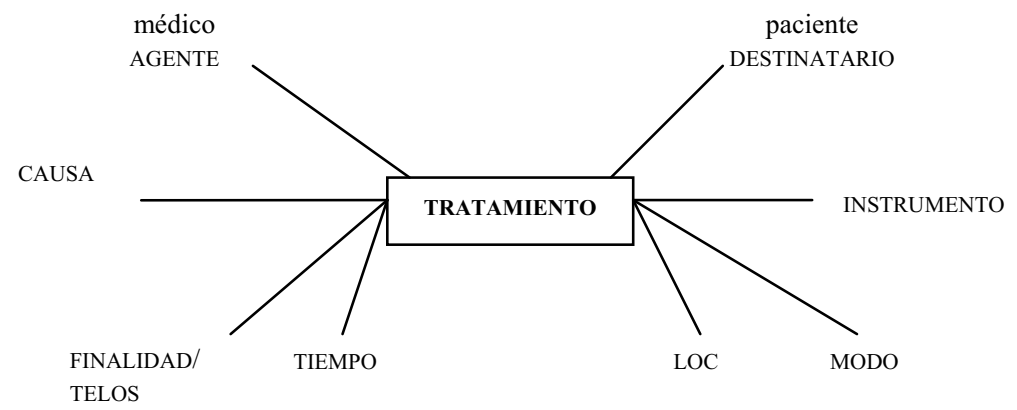

Las CC meta evocadas por los textos meta en la mente de los receptores pueden carecer de ciertos partícipes integrantes de las $\mathrm{CC}$ fuente $\mathrm{o}$ diferenciarse en cuanto a las lexías que suelen prototípicamente llenar las casillas vacías para los partícipes caracterizados por el papel temático que pueden desempeñar en el evento, el suceso o la actividad conceptualizados por la CC en cuestión. En tales casos, el traductor tiene que hacer todo lo que esté en su mano para compensar las carencias o divergencias: podrá utilizar, por ejemplo, recursos léxicos suplementarios para especificar lo que pertenece a los conocimientos previos compartidos de los receptores fuente.

No les resulta a los traductores tarea nada fácil intentar compensar eventuales lagunas designativas, pero suele ser menos complicado que reestructurar las configuraciones cognitivas o eliminar de estas CC meta determinados partícipes no admitidos o coactivados por la CC fuente. Resulta particularmente difícil obstaculizar la evocación de rasgos designativos compartidos en las conceptualizaciones y conocimientos previos de los receptores meta que designan aspectos connotativos, en especial negativamente evaluados, donde en la CC fuente 
no aparece ningún rasgo parecido o incluso donde aparece un rasgo apreciativo positivo. Opinamos que en este último caso el traductor no podrá evitar una cierta divergencia en los valores o efectos comunicativos fuente y meta, al igual que en aquellos casos donde los receptores meta suelen coactivar automáticamente una $\mathrm{CC}$ suplementaria junto a la CC coactivada en concordancia con la $\mathrm{CC}$ evocada en el texto fuente y donde esta $\mathrm{CC}$ meta suplementaria introduce rasgos denotativo-referenciales y designativo-connotativos difíciles y hasta imposibles de eliminar por los esfuerzos traductivos.

El mensaje textual viene constituido no solo por las unidades léxicas como elementos de lo dicho, sino puede abarcar también lo que aportan otros recursos semióticos materializados o textualizados; forman parte también de lo puesto $\mathrm{y}$, como lo hemos demostrado con las unidades léxicas, estos otros signos no dejan de aportar con su contenido una determinada parte de lo supuesto, bajo forma de $\mathrm{CC}$ evocadas o evocables y parcialmente congruentes con el semantismo de la palabra.

Sin embargo, cuando hablamos de lo supuesto, nos referimos también y ante todo a otros conocimientos previos que el receptor de un texto suele activar -automáticamente o, en caso de necesidad designativa, conscientemente- de entre el conjunto de conocimientos compartidos, adquiridos y almacenados en actos comunicativo-designativos anteriores $\mathrm{y}$, por ende, disponibles, ya que los receptores los han considerado lo suficientemente pertinentes como para memorizarlos.

En el discurso entre expertos pueden quedar implícitos no pocos conocimientos enciclopédicos, porque podrán activarse recurriendo a lo supuesto disponible en sus mentes. En un discurso de experto a experto en un texto fuente, que tendría que servir de base para producir un texto meta dirigido a legos en la materia tratada, puede resultar inevitable textualizar los conocimientos implícitos en el texto fuente para asegurar la comprensión del mensaje y la activación de un conjunto de CC máximamente congruentes en las conceptualizaciones de cada receptor meta. En tales casos, al producir el texto meta puede ser preciso transformar radicalmente la correlación entre lo explícito/ puesto y lo implícito/ supuesto del texto fuente.

No sólo hemos aprendido, acumulando experiencias vitales que aparecen interiorizadas como escenas reales o "pequeños dramas" vi- 
vidos con una determinada calidad y cantidad de co-partícipes; también hemos adquirido conocimientos sobre interrelaciones e interconexiones posibles entre diversas $\mathrm{CC}$, y disponemos de conocimientos enciclopédicos compartidos y estructurados en configuraciones cognitivas de muy variada índole, que podemos activar no mediante un semantismo verbal, es decir junto con una CC semánticamente indicada (lo supuesto coactivable por lo puesto), sino a partir de una complexión de $\mathrm{CC}$ ya almacenada en su conjunto. También podemos activar una determinada CC no incidida directamente por una unidad léxica verbal, basándonos en la situación discursiva-enunciativa hic et nunc donde aprovechamos la percepción visual o auditiva extralingüística disponible. Gracias a esos conocimientos enciclopédicos adquiridos con anterioridad y memorizados por necesidades designativas o comunicativas podemos recurrir a $\mathrm{CC}$ de lo supuesto no directamente indicadas por recursos lingüístico-semióticos, utilizando estrategias inferenciales que también hemos aprendido a manejar al igual que, por ejemplo, mecanismos conceptogenésicos de la llamada semántica procedimental o dinámica, que nos ayudan mediante transposiciones metonímicas, metafóricas y sinestéticas a ampliar el potencial designativo aprovechable junto con las unidades léxicas ya existentes y su semantismo/ medioestructura ya acuñados.

Lo supuesto, o lo sobreentendido directamente indicado o inferencialmente inducido, desempeña un papel más o menos importante, pero nunca omisible en la construcción del mensaje como componente esencial del sentido comunicativo del texto. En la comunicación monolingüe entre expertos y legos pueden darse dificultades de comprensión justamente porque los legos no disponen de las CC de lo supuesto, inferidas por los expertos gracias a que éstos las han adquirido en unión de las interrelaciones prototípicas que ostentan las CC inducidas con la(s) CC indicada(s) por recursos lingüísticos y/o semióticos.

¿Podrá hablarse todavía de haber logrado un texto meta comunicativamente adecuado si los cambios indispensables para una textualización en la lengua meta de lo supuesto implícito e inferible en el texto fuente han sobrepasado considerablemente los límites y han dado lugar a un texto meta de, digamos, cuatro páginas para un original de solo media página? Si mantenemos nuestro postulado de máxima congruencia entre los mensajes fuente y meta, tendríamos de hecho que tolerar cualquier ampliación del texto meta mediante la explicitación y 
materialización con recursos léxicos y semióticos meta, si es que solamente así se puede compensar la carencia de CC o la imposibilidad de inferir CC implícitas, pero indispensables para obtener un mensaje meta máximamente congruente / equivalente. Creemos que incluso en el caso de un diferencial tecnológico muy grande entre países europeos y/o latinoamericanos, no llegaríamos a ampliaciones tan exageradas y podríamos garantizar, pues, un texto meta comunicativamente equivalente y aceptable como traducción; se complicaría la decisión si un texto meta necesariamente muy ampliado no fuera compatible con las convenciones textuales imperantes en la lengua meta; pero creemos que aquí también sólo se trata de un fenómeno teórico sin importancia práctica real.

A la estrecha interpenetración que se da en el mensaje textual entre lo puesto y lo supuesto suele sobreponerse lo que ha querido decir el autor, lo cual empieza a interesar al traductor si la intención perseguida con el texto fuente no coincide con lo que se dice en el texto, sino que se trata de una intención informativa coincidente con la función informativa garantizada por el mensaje en cuestión y sobre todo por lo dicho o lo textualizado (cf. los problemas específicos que se desprenden de una interacción de dibujos y texto en cómics - Schmitt 1997; Jüngst 2007 y Wotjak 1998). En el habla oral, y en particular en su realización prototípica, el diálogo, el destinatario del mensaje discursivo puede recurrir a la situación discursivo-enunciativa acompañante, la deixis EGO-HIC-NUNC (Bühler 1934), ante todo a los gestos y a la mímica del locutor para averiguar si lo puesto, lo dicho y gestualmente indicado, es realmente lo que ha querido decir, y para identificar así la función ilocucionaria y/o el objetivo perlocutorio perseguido, es decir, lo intencionado por el autor/ locutor.

Estas posibilidades complementarias, muy útiles para indicar e identificar lo intencionado y que revisten particular importancia cuando divergen lo dicho y lo que se ha querido decir, escasean o desaparecen por completo en los textos escritos que sirven de base para la traducción. Poyatos (2002) ha hablado de channel reduction y la ha descrito con lujo de detalles; indicaciones metacomunicativas y el uso de recursos de maquetación no compensan siempre las indicaciones supra-segmentales y gestuales del habla oral. A lo largo de nuestra praxis comunicativa e interaccional hemos adquirido un inventario de fórmulas comunicativas, cuya aportación semántico-designativo-refe- 
rencial al sentido comunicativo dista mucho de una lectura literal de la macroestructura semántica-sintagmática-oracional respectiva. Ya no tenemos que ver con actos directos de habla, sino que nos enfrentamos a actos indirectos en los que la función ilocucionaria perseguida no concuerda con el significado modal oracional como en (2):

(2) ¿Está abierta la ventana?

Si los interlocutores se dan cuenta de que la ventana está abierta y le conceden al locutor suficiente lucidez para poder darse cuenta de ello, empezarán a deducir otra función distinta de la interrogativa. Habrán aprendido que se suelen utilizar preguntas que no requieren respuestas verbales, sino que funcionan como peticiones y persiguen una intención perlocutiva de incitar al destinatario a hacer "algo". Este algo se deducirá a partir de la situación discursiva-enunciativa concreta y llevará a los destinatarios del mensaje (2) a actuar - cerrando la ventana cuando hay mucho frío, tal vez abriendo otra ventana o la puerta cuando hace calor, muchas veces no sin asegurarse antes verbalmente de que tal ha sido la intención real del locutor.

En el enunciado (3) vemos que pueden darse dos lecturas discursivas: una literal (como pregunta a la que podemos responder que sí, o explicar por qué no nos es posible hacer lo solicitado); otra, en la que podemos atribuirle un valor funcional distinto que aumenta considerablemente la idea de que se necesita una ayuda o actuación correspondiente.

(3) ¿No podrías echarme una mano en el jardín?

La lectura literal como acto directo interrogativo (A) podría requerir una respuesta como la siguiente: "Sí, por supuesto, con mucho gusto (te ayudaré)". También podría interpretarse ese mismo enunciado como un reproche (B) y adquiriría fuerza incitativa; se acudiría a una lectura como acto indirecto de habla; lo cual habría podido expresarse asimismo en un acto de habla directo mediante el enunciado siguiente reformulado: „¿Por qué no me ayudas en el jardín?". Para la traducción al alemán se aconsejarían tres versiones distintas como en (4a, 4b y $4 c)$. 
(4a) Könntest Du mir nicht im Garten zur Hand gehen?

(4b) Geh' mir doch (bitte) mal im Garten zur Hand! ${ }^{10}$

(4c) Du könntest mir ja wirklich mal im Garten zur Hand gehen.

Pensamos que en el habla oral podrían encontrarse indicaciones tanto suprasegmentales entonatorias como tal vez gestuales o de mímica que nos facilitarían la decisión entre una lectura literal interrogativa (4a), una petición de ayuda (4b) y una lectura indirecta de reproche $(4 c)$.

(5) ¿Se baja/ apea usted también?

El enunciado (5) no nos sirve tanto para averiguar si otra persona se baja del autobús (generalmente no nos interesa una respuesta verbal sí o no) como para pedirle que nos deje salir en el caso de que ella no lo haga. No siempre se puede inferir la intención perseguida recurriendo a la situación discursivo-enunciativa concreta o a nuestro conocimiento de estrategias comunicativas que nos dicen que podemos sustituir actos de habla directos, en especial los incitativos o directivos, por actos indirectos en los que muchas veces recurrimos a preguntas para pedir algo o incitar una reacción perlocutoria apropiada. Hay casos en los que no somos capaces de comprender lo que ha querido decir el autor, ya que en el texto no descubrimos ninguna indicación de que no se haya querido decir lo que se ha dicho, o sea, de que se requiera una reinterpretación algunas veces diametralmente opuesta a la lectura literal dada.

En no pocos casos, las modificaciones convencionalizadas de la lectura literal de una secuencia dada de palabras o fórmula comunicativa rutinaria como en (6) se deben a códigos de cortesía que pueden diferir bastante entre dos idiomas y comunidades paraculturales.

${ }^{10}$ Función ilocucionaria imperativa directa bastante fuerte o menos insistente como reproche, pero también con un cambio del significado oracional modal de interrogativo a asertativo y recurriendo a toda una serie de partículas modales como en (4c). 
(6) Vamos a pensarlo. Me lo pensaré. Vamos a pasarlo al organismo superior. (Cuba)

Un alemán no sensibilizado con la cortesía española (que también se manifiesta cuando alguien dice: "Ésta es su casa", pero no lo interpreta como invitación a pasar en ella unos días) volverá a preguntar a su interlocutor español después de unos meses: "¿Se lo ha pensado por fin?", disimulando con dificultad su desagrado por el incumplimiento de la promesa hecha en el enunciado mencionado; si se acumulan tales situaciones se consolidará en su mente el prejuicio de que los españoles mucho prometen, pero raras veces cumplen. El español, por su lado, se sentirá molesto y, tal vez, confirmado en el prejuicio de que los alemanes son bastante brutos y directos, ya que para él nunca se habría podido interpretar su aparente promesa de otra manera que como rechazo definitivo, si bien cortés e indirecto, análogo a un acto de habla directo, incompatible con los preceptos de cortesía imperantes, que equivaldría a: "No lo pensaré nunca más". Algo parecido ocurre cuando un brasileño dice: Te ligarei amanhã, ya que todos saben que no piensa llamar por teléfono.

Para los ejemplos citados, en los que la macroestructura semántica-sintagmática-oracional, al menos en parte (lectura literal como enunciado interrogativo), si no por completo, recibe una reinterpretación funcional-intencional con un sentido comunicativo ilocucionario divergente (ejemplo 4; lectura indirecta incitativa), se observa un cambio de la función comunicativa que el receptor efectúa basándose en su cooperatividad y en el conocimiento compartido de la situación discursivo-enunciativa, o bien en su conocimiento cabal de estrategias comunicativas para conseguir un objetivo perlocucionario dado [una petición de hacer algo]. Habrá aprendido que en la comunidad idiomático-paracultural predominan actos indirectos de habla donde aparentes preguntas sustituyen a actos de habla directos directivo-imperativos. Las razones que guían su decisión son preferentemente de índole sociocultural-interaccional y puede haber diferencias subjetivas en la selección de tales estrategias indirectas, o bien estas últimas pueden depender de la simetría o asimetría socio-interaccional existente entre los comunicantes.

La selección de enunciados rutinarios del tipo mencionado en (6) claramente depende, sin embargo, del código de cortesía imperan- 
te. Ya no se trata de modificaciones pragmático-situativo-comunicativas, sino que estas fórmulas comunicativas, independientemente del contexto enunciativo, ya quieren decir lo contrario (= lectura intencional funcionalmente transpuesta, pero ya usualizada y socializada) de lo que se dice (lectura literal de la combinatoria libre no transpuesta

= macroestructura semántica sintagmática).

Hasta ahora nos hemos ocupado exclusivamente de los factores que influyen directamente en el sentido comunicativo del texto como criterio fundamental para asegurar la equivalencia comunicativa del texto meta. En este contexto hemos destacado la importancia primordial del mensaje textual, constituido por lo puesto y lo supuesto, así como por lo que ha querido decir el autor del texto original, es decir, de un lado por la intención perseguida por él o, de otro lado, por la intención realizada por los receptores del mensaje. Al inicio habíamos insistido en que el traductor también debe tener en cuenta la adecuación comunicativa a la que dedicaremos las siguientes observaciones.

\section{Algunas observaciones relativas a la adecuación comunicativa y su relación con la equivalencia comunicativa}

La adecuación comunicativa postulada como segundo criterio para evaluar la calidad del texto meta traducido o adaptado ha sido tratada, a nuestro entender, de forma menos específica por la Escuela Traductológica de Leipzig (Jung 2003), por lo que a ello dedicaremos a continuación algunas aclaraciones. No utilizaremos el concepto de adecuación comunicativa para designar con él la adecuación del texto meta a los conocimientos previos, en particular, a los conocimientos socioculturales más o menos divergentes de los receptores meta. Tampoco quisiéramos hablar aquí de adecuación al encargo o al escopo perseguido con el texto meta. Al hablar de adecuación comunicativa nos referimos fundamentalmente a las siguientes tareas/necesidades: (a) escoger aquellas unidades léxicas cuyas características comunicativo-pragmático-situativas (indicadas en el plano de la expresión del potencial-comunicativo de las unidades léxicas -fig. 1) se adecuen óptimamente a la esfera comunicativa y a la situación discursivo-enunciativa en la que interactúan los interlocutores; (b) escoger aquellas combinaciones de unidades 
léxicas/ enunciados minimales que suelen utilizarse normativamente para realizar determinadas microfunciones comunicativas prototípicas (Vilar Sánchez 2007) y producir microestructuras textuales que se adecuen óptimamente a las convenciones textuales del tipo de texto en cuestión y (c) respetar al máximo la arquitectura textual, es decir la macroestructura, que puede divergir bastante entre texto fuente y texto meta, por ejemplo, en los textos jurídicos.

Como veremos a continuación, no resulta fácil decidir si nos enfrentamos a un fenómeno de equivalencia comunicativa o de adecuación comunicativa. Podría incluso postularse un concepto más amplio de equivalencia comunicativa que (además de la congruencia óptima del sentido comunicativo, con sus componentes mensaje e intención o función comunicativa del texto y/o de pasajes infratextuales) también abarque aspectos suplementarios de la adecuación comunicativa. Esta última englobaría, además de la adecuación del mensaje a la situación discursivo-enunciativa, la adecuación a las normas o convenciones del tipo de texto en cuestión (microestructuras y macroestructura textuales).

Si seguimos fieles a la propuesta inicial, el criterio decisivo para la caracterización de las divergencias inevitables en la confección del texto meta frente al texto fuente será la divergencia observable entre el sentido comunicativo del enunciado y la carga designativo-referencial indicada por la combinación de las unidades léxicas en la lectura literal de la macroestructura semántica sintagmática correspondiente (ej. 2 y 6). En ejemplos como (6), comparables a (7), la discrepancia designativa de la lectura literal se encuentra ya convencionalizada y podemos atribuirle a esta secuencia de unidades léxicas -al igual que a los fraseologismos idiomáticos (Wotjak 2004) - un significado transpuesto, modificado. Para ello no tenemos que recurrir a inferencias sobre la situación discursivo-enunciativa concreta que nos ayuden a elegir la lectura intencionada y excluir la otra coexistente a nivel de la norma, como en (8a y 8b).

(7) Du bist mir ja ein schöner Freund!

¡Qué buen amigo eres!

(8a) Das ist ja wirklich eine schöne Überraschung!

Eso sí que es una buena sorpresa.

(8b) ¡No te imaginas como se comportó este tío! 
Si el traductor - para asegurar que el texto meta sea comunicativamente adecuado- recurre, por ejemplo, a construcciones verbales o activas donde el texto fuente utiliza construcciones nominales y pasivas, ya no se trata de fenómenos que pertenecen a la equivalencia comunicativa en sentido estricto. Lo mismo es válido para cambios en la arquitectura textual con el objeto de satisfacer las convenciones textuales imperantes en la lengua meta. Sin embargo, si debemos recurrir al uso de enunciados que en su totalidad o en parte señalan modificaciones semántico-designativas, como, por ejemplo, en (9), ¿deberíamos optar por incluir estos casos de adecuación al uso situativo y discursivoenunciativo, tal vez, en la misma categoría que lo tratado en (6), pese a que las razones que puedan alegarse para su uso sean bastante distintas?

(9) Craint la pluie

Esta fórmula rutinaria suele utilizarse en francés para expresar que no hay que exponer algo a la humedad. Se reproduciría totalmente su carga designativo-referencial si utilizáramos enunciados semánticamente equivalentes como: Ne pas exposer à l'humidité! o À abriter de l'humidité!. Los hablantes meta, sin embargo, dirían que entienden en tales enunciados lo que se dice y también lo que se ha querido decir, gracias a las lexías indicadoras del acto de habla (imperativo), pero que no se diría así.

El hecho de no considerar lo dicho en consonancia con lo que se suele decir, es un importante argumento a favor de calificar tales enunciados como candidatos a la adecuación comunicativa. En tales casos también podríamos alegar a favor de la adecuación comunicativa la nocoincidencia de las funciones ilocucionarias indicadas mediante el significado modal oracional (imperativo frente a asertativo en Craint la pluie).

A pesar de que las macroestructuras semánticas sintagmáticas de Craint la pluie y de los posibles, pero comunicativamente inadecuados enunciados mencionados sean bastante divergentes, se están instanciando estados de cosas, configuraciones cognitivas compartidas, bastante y hasta totalmente congruentes. Ello las califica como virtuales equivalentes comunicativos, ya que coactivan un mensaje designativa- 
mente coincidente y también garantizan la identidad de lo que se ha querido decir.

En este contexto podemos reproducir también el ejemplo del latín aqua!, enunciado monolexemático con función directivo-incitativa que representa un acto de habla directo, y que tendría como enunciados "equivalentes comunicativos", quizá mejor denominados traslémi$\cos$, las unidades léxicas meta correspondientes indicadas en (10). Pese al recurso a una unidad léxica meta con un significado léxico distinto que coactiva una perspectivación epistemológica divergente, en la mente de los receptores franceses, españoles y alemanes se actualiza una misma escena así como una misma función perlocucionaria implícita: "¡Ayudad en la extinción del incendio!". Mientras que los romanos aseguraban la evocación rutinaria y convencionalizada de la configuración cognitiva mediante la indicación del agua como recurso esencial para garantizar la extinción del fuego/ incendio, los miembros de las tres otras comunidades idiomático-culturales mencionadas evocan una CC fundamentalmente congruente y considerada igual de pertinente e indicadora de alarma que aquellas unidades léxicas que designan lo que hay que extinguir, o sea, el DESTINATARIO/GOAL de la acción requerida de extinción y no el INSTRUMENTO, que hay que utilizar y que en la actualidad ya no sería aconsejable para extinguir cualquier tipo de incendio.

(10) aqua! $\rightarrow$ francés: Au feu!; español: ¡Fuego!; alemán: Feuer!

Algo parecido ocurre en (11), donde el uso de "adentro" en el enunciado respectivo no es ni designativa ni comunicativamente conciliable con el adverbio alemán hinaus; aquí se manifiesta una perspectiva distinta del estado de cosas designado y obligatoriamente expresado tanto por los hablantes del español y como del alemán, que resaltan respectivamente: "adentrarse en el mar" opuesto a "alejarse entrando en el mar".

(11) Mi tía se fue / nadó muy adentro en el mar y le costó mucho volver a la playa.

Meine Tante schwamm sehr weit ins Meer hinaus und hatte alle Mühe, wieder zum Strand zurückzukommen. 
Debemos aceptar que los españoles prefieran una perspectiva distinta, que tal vez refleja una cosmovisión diferente de la de los alemanes, y podemos buscar la causa, pero hemos de aceptar la convención discursivo-enunciativa del español.

Debemos hacerlo también en el caso del enunciado francés (12), en el que la prohibición de escupir nos choca bastante y donde nos inclinaríamos a dejar caer la última parte del enunciado que, sin embargo, parece tan fuertemente estereotipado y congelado en el uso que incluso consta en elegantes y ultramodernos autobuses franceses, como hemos podido observar en un viaje del aeropuerto de Frankfurt a Estrasburgo.

\section{(12) Défense de fumer et de cracher.}

Resumiendo, podemos comprobar que siempre hemos de asegurar la adecuación comunicativa, es decir, garantizar que el texto meta contenga enunciados discursivo-enunciativos usuales, que los hablantes de esta lengua acostumbren a utilizar para designar un determinado estado de cosas y expresar una determinada intención comunicativa. Por suerte, sólo en contados casos el traductor se enfrenta al hecho de que la unidad léxica meta (indicada en un buen diccionario bilingüe como un equivalente semántico-designativo denotativo-referencial y connotativo total o parcial) no se pueda utilizar porque se produciría un enunciado que ya no se diría así, es decir, que no se adecua a las normas de uso convencionalizadas (adentro y no afuera para el uso enunciativo de hinaus en el enunciado 11).

Solo adquirimos consciencia de que debemos recurrir a adecuaciones comunicativas complementarias si nos percatamos de que hay unas convenciones designativo-comunicativas distintas. El análisis pormenorizado de textos paralelos o bien los resultados de una estilística comparada nos ayudarán a percibir tales divergencias en el uso de unidades léxicas y enunciados semánticamente divergentes e incluso designativamente bastante coincidentes. Nos guiaremos por la divergencia de las lecturas literales, principalmente las macroestructuras semánticas sintagmáticas, entre el texto fuente y el texto meta.

En lugar de hablar de equivalentes comunicativos en el caso de enunciados o partes de enunciados que de hecho garantizan la adecua- 
ción comunicativa, quizá sea más conveniente no hablar de equivalentes comunicativos sino de traslemas aprovechando la terminología acuñada por la Escuela Traductológica de León y su fundador, nuestro homenajeado. Estas últimas garantizarían un sentido comunicativo máximamente congruente del texto meta y también su óptima adecuación comunicativa.

Las CC activadas por la secuencia de las unidades léxicas traslémicas, que constituyen macroestructuras semánticas-sintagmáticas más o menos divergentes, pueden diferir o coincidir cabalmente, o sea, pueden también tener que ver con perspectivaciones y modalizaciones semántico-designativas más o menos grandes, que se mantienen tal cual en la constitución del mensaje textual y sentido comunicativo o que desaparecen a consecuencia de reinterpretaciones que buscan lo que realmente se ha querido decir.

\section{Resumiendo: ¿Cómo podemos asegurar que el texto meta producido por el traductor sea comunicativamente equivalente y adecuado?}

Debemos efectuar un análisis pormenorizado semántico-designativodenotativo-referencial y connotativo, así como situativo-discursivoenunciativo intencional, del texto fuente para tener presente su sentido comunicativo. A continuación debemos escoger los recursos semiótico-lingüísticos que suele utilizar la comunidad paracultural (o diacultural-profesional) e idiomática meta para designar estados de cosas, eventos, sucesos, estados físicos y fisiológico-sicológicos, propiedades, etc. así como moldes o patrones de conducta interaccional y apreciativa convencionalizada.

En este complejo proceso onomasiológico $\rightarrow$ semasiológico y top-down, el traductor tiene que tener en cuenta las múltiples divergencias existentes en los conocimientos previos compartidos por los receptores meta con el fin de intentar subsanar las probables carencias y minimizar el efecto de la existencia de actitudes y evaluaciones divergentes. No siempre podrá evitar pérdidas, pero puede hacer todo lo posible para disminuir su cantidad y sus consecuencias para la comprensión del mensaje y de lo que el autor del original ha querido decir. En esto puede confiar: en que no todos los elementos del mensaje ori- 
ginal son comunicativamente igual de pertinentes, en que se puede establecer una cierta gradación en cuanto a la relevancia comunicativa de las múltiples configuraciones cognitivas coactivables en la isotopía y progresión temática y en que todos los hablantes disponemos de una gran voluntad y capacidad de inferencia y abducción. Gracias a esa capacidad y cooperatividad, los receptores de un mensaje logran subsanar no pocas lagunas y discontinuidades lógico-argumentativas y detectar lo que el autor ha querido decir, más allá de la siempre presente intención informativa.

En el no menos complicado proceso de selección de aquellos recursos semiótico-lingüísticos que mejor vehiculen el mensaje y expresen la intención comunicativa del texto fuente con vistas a la producción de un texto meta óptimamente equivalente y comunicativamente adecuado, el traductor debe solucionar muchas dificultades y proceder a múltiples decisiones para encontrar la unidad léxica más apropiada entre los varios recursos léxicos y morfosintácticos disponibles para el estado de cosas que desea designar y para la situación discursivoenunciativa concreta a la que hace referencia el enunciado o la palabra elegidos. Asimismo, debe considerar las convenciones textuales de la lengua meta virtualmente divergentes de las del tipo de texto fuente y, por regla general, readaptar el texto meta a la arquitectura macroestructural meta y a las preferencias de uso vigentes en las microestructuras textuales, y, no en última instancia, hallar las unidades léxicas y enunciados traslémicos existentes o aún por crear.

\section{Bibliografía}

Bierwisch, Manfred. 1983. "Semantische und konzeptuelle Repräsentation lexikalischer Einheiten”. En Untersuchungen zur Semantik, R. Růžička y W. Motsch (eds). Berlin: Akademie [Studia Grammatica, XXII]. 61-99.

Bühler, Karl. 1934. Sprachtheorie. Jena: Fischer.

Campos Plaza, Nicolás A. y Ortega Arjonilla, Emilio. 2005. Panorama de lingüística y de traductología. Granada: Atrio, Ediciones de la Univ. de Castilla-La Mancha. 
Cardozo, Maurício, Heidermann, Werner y Weininger, Markus J. (eds). 2009. A Escola Tradutológica de Leipzig. Frankfurt am Main: Peter Lang.

Coseriu, Eugenio. 1977. "Lo erróneo y lo acertado en la teoría de la traducción". En El hombre y su lenguaje: Estudios de teoría y metodología lingüistica. Madrid: Gredos. 214-239.

Ducrot, Oswald. 1972. Dire et ne pas dire: Principes de sémantique linguistique. Paris: Hermann.

Fillmore, Charles J. 1976. "Frame Semantics and the Nature of Language". En Annals of the New York Academy of Science, 280. New York. 20-31.

García Peinado, Miguel Á. y Ortega Arjonilla, Emilio (dir.). 2003. Panorama actual de la investigación en Traducción e Interpretación. Vol. I y II. Granada: Atrio.

García Yebra, Valentín. 1982: Teoría y práctica de la traducción. Madrid: Gredos. [Biblioteca Románica Hispánica, III; manuales 53; 2 vol.].

Große, Rudolf y Neubert, Albrecht. 1974: "Thesen zur marxistischleninistischen Soziolinguistik". En Beiträge zur Soziolinguistik, R. Große y A. Neubert (hrsg.). Leipzig: Enzyklopädie. 25-46.

Gutt, Ernst-August 1991. Translation and Relevance: Cognition and Context. Oxford: Oxford University Press.

Helbig, Gerhard. 1992. Probleme der Valenz- und Kasustheorie. Tübingen: Niemeyer.

Hurtado Albir, Amparo. 2001. Traducción y Traductología: Introducción a la Traductología. Madrid: Cátedra.

Írsula Peña, Jesús. 1994. Substantiv-Verb-Kollokationen: Kontrastive Untersuchungen Deutsch-Spanisch. Frankfurt am Main: Peter Lang.

Jäger, Gert. 1975. Translation und Translationslinguistik. Halle: Niemeyer.

Jüngst, Heike. 2007. Information Comics. Knowledge Transfer in a Popular Format. Tesis de habilitación leída en la universidad de Leipzig. Inédita.

Jung, Linus. 2000. La Escuela Traductológica de Leipzig. Granada: Comares.

Jung, Linus. 2003. "Zum Verhältnis von kommunikativer Funktion und kommunikativer Äquivalenz”. En Brückenschlag. Beiträge 
zur Romanistik und Translatologie. Gerd Wotjak zum 60. Geburtstag, M. Emsel y A. Hellfayer (eds). Frankfurt am Main: Peter Lang. 219-234.

Jung, Linus y Jiménez Hurtado, Catalina. 2005². "Más allá del funcionalismo: skopos y equivalencia comunicativa". En Panorama actual de la investigación en traducción e interpretación. Emilio Ortega Arjonilla (dir.). Granada: Atrio (en CD), vol. I. 183-194.

Kade, Otto. 1968. Zufall und Gesetzmäßigkeit in der Übersetzung. Leipzig: Enzyklopädie.

Kade, Otto. 1980. Die Sprachmittlung als gesellschaftliche Erscheinung und Gegenstand wissenschaftlicher Untersuchung. Leipzig: Enzyklopädie. [Übersetzungswissenschaftliche Beiträge, vol.3].

Klix, Friedhart. 1987. "On the Role of knowledge in sentence comprehension". En Preprints of the Plenary Session Papers (XIVth International Congress of Linguists). Berlin. 111-124.

Koller, Werner. $1992^{4}$. Einführung in die Übersetzungswissenschaft. Heidelberg: Quelle.

Lederer, Marianne. 1994. La traduction aujourd'hui: Le modèle interprétatif. Paris: Minard.

Lefevere, André 1996. Traducción, reescritura y la manipulación del canon literario. Salamanca: Ediciones Colegio de España.

Lvovskaya, Zinaida. 1997. Problemas actuales de la traducción. Granada: Método Ediciones.

Neubert, Albrecht. 1977. "Zur kommunikativen Äquivalenz". En Linguistische Arbeitsberichte. (LAB). Vol.16. Leipzig. 15-22.

Neubert, Albrecht. 1985. Text and Translation. Leipzig: Enzyklopädie [Übersetzungswissenschaftliche Beiträge, vol. 8].

Newman, Aryeh. 1980. Mapping Translation Equivalence, Leuven: Academic Publishing Company.

Nida, Eugene A. 1964. Toward a Science of Translating, with special reference to principles and procedures involved in Bible translating. Leiden: E. J. Brill.

Nida, Eugene A. 1975. Language Structure and Translating. Stanford, Ca.: Stanford University Press.

Nord, Christiane. 1997. Translating as a Purposeful Activity: Functionalist Approaches Explained. Manchester, UK: St. Jerome.

Nord, Christiane. 2002. Fertigkeit Übersetzen. Alicante: Editorial Club Universitario. 
Poyatos, Fernando. 2002. Non verbal communication. Amsterdam y Filadelfia: John Benjamins.

Pym, Anthony. 1998. Method in Translation Theory. Manchester, UK: St. Jerome.

Rabadán, Rosa. 1991. Equivalencia y traducción. Problemática de la equivalencia translémica inglés-español. León: Universidad de León.

Raskin, Viktor. 1985. "Script-based Semantics: a brief outline". En Quaderni di semantica 2: 306-313.

Raskin, Victor. 1986. “Once again on scripts”. En Quaderni di semantica 1: 101-106.

Reiss, Katharina y Vermeer, Hans J. 1996. Fundamentos para una teoría funcional de la traducción. Madrid: Akal.

Sáez Hermosilla, Teodoro. 1994. El sentido de la traducción: reflexión y crítica. León: Universidad de León / Salamanca: Universidad de Salamanca.

Salevsky, Heidemarie. 2002. Translationswissenschaft: Ein Kompendium. vol.1. Frankfurt am Main: Peter Lang.

Santoyo, Julio César. 1985/1989. El delito de traducir. León: Universidad de León.

Santoyo, Julio César. 1987. Traducción, traducciones, traductores: Ensayo de bibliografía española. León: Universidad de León.

Santoyo, Julio César. 1988. "Pragmatic Aspects of Translation: Textfocused vs. Reader-focused Equivalence". En Textlinguistik und Fachsprache. R. Arntz (Hg). Hildesheim/ Zurich/ New York: Georg Olms Verlag. 103-111.

Santoyo, Julio César (ed). 1988a. Translation Across Cultures: Actas del XI Congreso AEDEAN. León: Universidad de León.

Santoyo, Julio César. 1999. Historia de la traducción: Quince apuntes. Universidad de León.

Santoyo, Julio César. 2004. "Self-Translation: Translational Competence Revisited (and Performance as Well)". En Translationskompetenz. E. Fleischmann, P. A. Schmitt y G. Wotjak (eds). Tübingen: Stauffenburg: 223-236.

Schmitt, Peter A. 1997. "Comics and Cartoons: (k)ein Gegenstand der Übersetzungswissenschaft?" En Transfer. Übersetzen - Dolmetschen - Interkulturalität. H. W. Drescher (ed). Frankfurt am Main: Peter Lang. 
Schreiber, Michael. 1993. Übersetzung und Bearbeitung: Differenzzierung und Abgrenzung des Übersetzungsbegriffes. Tübingen: Narr.

Seleskovitch, Danica y Lederer, Marianne. 1984. Interpréter pour traduire. Col. Traductologie, 1. Paris: Didier Érudition.

Snell-Hornby, Mary. 1988. Translation Studies: An Integrated Approach. Amsterdam y Filadelfia: John Benjamins.

Snell-Hornby, Mary. 1999. Estudios de traducción. Hacia una perspectiva integradora. Tr. de Ana Sofía Ramírez. Salamanca: Almar.

Snell-Hornby, Mary, Pöchhacker, Franz y Kaindl, Klaus (eds). 1994. Translation Studies: An Interdiscipline. Ámsterdam y Filadelfia: John Benjamins

Sperber, Dan y Wilson, Deirdre. 1986. Relevance: Communication and Cognition. Oxford: Blackwell.

Tesnière, Lucien. 1959. Éléments de syntaxe structurale. Paris: Klincksieck.

Toury, Gideon. 1995. Descriptive Translation Studies - and beyond. Ámsterdam y Filadelfia: John Benjamins.

Trujillo, Ramón. 1988. Introducción a la semántica española. Madrid: Arco Libros.

Vannerem, Mia y Snell-Hornby, Mary. 1986. "Die Szene hinter dem Text: scenes and frames semantics in der Übersetzung". En Übersetzungswissenschaft - eine Neuorientierung. Zur Integrierung von Theorie und Praxis. M. Snell-Hornby (ed). Tübingen: Francke (UTB 1415): 184-205.

Vermeer, Hans J. 1996. A Skopos Theory of Translation: Some Arguments for and against. Heidelberg: TEXTconTEXT.

Vidal Claramonte, Carmen A. 1995. Traducción, manipulación, deconstrucción. Salamanca: Ediciones Colegio de España.

Vidal Claramonte, Carmen A. 1998. El futuro de la traducción: Últimas teorías, nuevas aplicaciones. Valencia: Institució Alfons el Magnànim.

Vilar Sánchez, Karin (ed). 2007. Mikrofunktionen in Arbeitsverträgen deutsch-spanisch. Frankfurt am Main: Peter Lang [CD ISBN 978-3-03911-314-9].

Wilss, Wolfram. 1996. Knowledge and Skills in Translator Behaviour. Amsterdam y Filadelfia: John Benjamins. 